\title{
GOVERNANÇA DE RECURSOS COMPENSATÓRIOS: OS DESAFIOS PARA A CONSTRUÇÃO DO FUNDO J\&F
}

\author{
Michael Freitas Mohallem \\ Isabel Cristina Veloso de Oliveira
}

\section{// resumo}

Em 2017, um acordo firmado entre a holding J\&F Investimentos S/A (J\&F) e o Ministério Público Federal (MPF), no âmbito da atuação da Procuradoria Regional do Distrito Federal, resultou em multa no valor de R\$ 10,3 bilhões. Desse montante, um total de R\$2,3 bilhões deverá ser destinado a projetos sociais por meio de um fundo próprio. Tais desdobramentos judiciais apresentam dois desafios: estruturar a entidade responsável pela distribuição dos fundos e superar os obstáculos para sua governança. Neste artigo, busca-se levantar por meio de análise teórica, entrevistas e dados estatísticos um conjunto de práticas de governança e transparência que possam ser úteis para orientar a construção e o desenvolvimento do Fundo $\mathrm{J} \& \mathrm{~F}$, bem como para que sirvam de referência a outros fundos voltados para a sociedade civil. A metodologia do estudo consiste em revisão bibliográfica, análise de dados quantitativos e qualitativos sobre fundos e entrevistas semi-estruturadas com gestores. Como resultado, aponta-se que o Fundo J\&F deve ser pautado na assunção de boas práticas de governança desde sua concepção, criando uma estrutura que não abra margem a déficits democráticos ou atos de corrupção. Para tal, deve-se moldar uma política que evite conflitos de interesse e que incentive uma composição plural dos membros e conselheiros/as. Ademais, a busca pela perenidade do fundo deve ser um ponto prioritário, mantendo, ainda, a transparência e a clareza quanto aos recursos investidos e seus destinatários.

| palavras-chave: Fundos | Investimento Social | Governança | J\&F 


\section{O GIFE}

O Grupo de Institutos Fundações e Empresas (GIFE) é uma organização sem fins lucrativos que reúne associados de origem empresarial, familiar ou independente que investem em projetos de interesse público. Criado em 1989 como grupo de troca e colaboração e institucionalizado em 1995 por 25 organizações, tornou-se referência no campo da filantropia e do investimento social privado no Brasil.

Nesses mais de 20 anos de atuação, tem contribuído para o fortalecimento de práticas e ações a serviço do bem comum no país, trabalhando para expandir, qualificar e fortalecer o investimento social privado, diversificar e ampliar atores e recursos, criando referências e estimulando boas práticas de gestão, bem como articulando o setor com a sociedade e a agenda pública. Atualmente, o GIFE reúne mais de 150 associados que, somados, aportam mais de R\$ 3 bilhões por ano em projetos próprios e no apoio a projetos de terceiros.

\section{OS ARTIGOS GIFE}

A série Artigos GIFE publica reflexões e análises de pesquisadores brasileiros de diferentes áreas do saber com o objetivo de estimular, ampliar e disseminar a produção de conhecimento qualificado sobre o campo da filantropia, do investimento social privado e da sociedade civil no Brasil.

A partir da premissa de que a produção de conhecimento sobre esses temas tem um papel fundamental na expansão, diversificação e qualificação da ação pública pela sociedade, a iniciativa também pretende contribuir para ampliar as conexões entre o setor, as universidades e centros de pesquisa, promovendo e apoiando o envolvimento de novos atores com a temática e a circulação ampliada de ideias em torno dela.

Este artigo integra a primeira edição dos Artigos GIFE que foram selecionados na chamada pública lançada pelo GIFE em 2018, com base na avaliação de um comitê externo. Os textos se enquadram em um dos 16 temas propostos e dialogam com dados do Censo GIFE 2016 ou de pelo menos uma das seguintes pesquisas: BISC 2017, Pesquisa Doação Brasil e Perfil das Organizações da Sociedade Civil no Brasil, conforme estabelecido no edital da chamada.

É com alegria que publicamos os primeiros artigos dessa iniciativa que, a partir de então, se propõe a ser contínua, buscando apoiar e fomentar a produção de conhecimento sobre esse campo no Brasil. 


\section{artigos \\ GIFE}

\section{INTRODUÇÃO}

A corrupção, desde que não obstruída por investigações, se mantém às sombras e seus danos permanecem imensuráveis. Os efeitos deletérios envolvem desequilíbrios econômicos, perda de credibilidade perante investidores e defasagens nas políticas públicas e produtividade dos países, dentre tantos outros. Este artigo analisa os elementos necessários para a construção de fundos reparatórios, mais especificamente aqueles destinados ao fortalecimento de mecanismos de enfrentamento da corrupção.

No Brasil, o emprego de recursos pecuniários oriundos de multas para projetos sociais como forma de reparar danos é uma prática mais conhecida na área ambiental. Nesse âmbito, o exemplo mais recente é o Fundo Samarco (MPF, 2017 a), criado para atenuar os danos causados pelo rompimento da barragem de rejeitos da mineradora no Vale do Rio Doce. No cenário internacional, começaram a ganhar destaque as experiências que resultam em acordos ou multas que destinam recursos compensatórios como forma de reparar os danos causados por crimes contra a administração pública ou contra a coletividade, tais como os emblemáticos exemplos do Fundo Siemens e do Fundo Alcatel ${ }^{1}$.

O acordo de leniência firmado entre a holding J\&F Investimentos S/A (J\&F) ${ }^{2}$ e o Ministério Público Federal, no âmbito da atuação da Procuradoria Regional do Distrito Federal, em junho de 2017, deu concretude a esse debate também no Brasil (MPF, 2017 b). Pelo acordo, a empresa se comprometeu a pagar um total de R\$ 10,3 bilhões parceladamente em 25 anos. Desse montante, o aporte total a ser investido em projetos sociais é de R\$ 2,3 bilhões. E é sobre os desdobramentos desse acordo de leniência e os consequentes desafios para construir um fundo de reparação que este artigo se debruça.

Dessa forma, em razão do ineditismo do acordo e da importância que a nova instituição gestora desse fundo de reparação terá para o país, este artigo tem como propósito fornecer elementos para subsidiar a criação da organização responsável pela administração e distribuição dos recursos para os setores relevantes

\footnotetext{
1 A Iniciativa de Integridade da Siemens foi estabelecida em 2009, na forma de um acordo realizado com o Banco Mundial. Seu principal objetivo é criar condições de mercado mais justas e combater a corrupção financiando projetos em tais áreas com aporte de US\$ 100 milhões em 15 anos (SIEMENS, 2016). O caso Alcatel ocorreu na Costa Rica, em 2006. A empresa foi, à época, acusada de ter transferido US\$ 15 milhões para uma consultoria visando obter contratos de redes celulares (OLAY, ATISSO e ROTH, 2010).
}

2 A J\&F Investimentos é uma holding brasileira criada em 1953 pertencente à família Batista. Dentre as empresas do grupo estão JBS, Flora e Banco Original. 
da sociedade civil, trabalho esse que vem sendo liderado pela Transparência Internacional $(\mathrm{TI})^{3}$, responsável pelo fornecimento de material empírico para subsidiar a criação do fundo e por sua formulação em $\mathrm{si}^{4}$.

Nesse cenário, algumas perguntas se mostram imperativas: como construir e estruturar um fundo justo e eficaz? Quais são os pontos sensíveis? Quais características se mostram cruciais? No intuito de lançar luz sobre essas questões, o presente trabalho analisa, dentre outros fatores, estudos teóricos e empíricos sobre fundos voltados para a sociedade civil, práticas de governança, transparência e accountability, modelos de investimento e códigos de conduta corporativa.

Além das abordagens teóricas, foram também consideradas as reflexões coletadas por meio de entrevistas com coordenadores e diretores de associações, fundos e fundações já estabelecidos no Brasil. A escolha dos entrevistados se deu em razão de seu amplo conhecimento sobre o campo da filantropia e investimento social privado no Brasil e no mundo.

O objetivo do artigo é, dessa forma, contribuir para o desenho de um modelo de fundo de investimento para a sociedade civil, capaz de fortalecê-la de modo duradouro e transformador. O artigo está estruturado em duas partes: (I) a primeira é dedicada a fornecer um panorama sobre os investimentos sociais privados no Brasil, onde será possível estimar comparativamente o impacto potencial da instituição do Fundo J\&F no fomento às organizações; (II) a segunda, por sua vez, destina-se ao debate dos pontos sensíveis à construção do fundo, apresentando perspectivas teóricas e práticas sobre o que seria um desenho ideal de fundo.

\section{0 INVESTIMENTO SOCIAL PRIVADO NO BRASIL}

O investimento social privado (ISP) costuma ser caracterizado pelo repasse voluntário de recursos, de pessoa física ou jurídica de direito privado, de forma planejada, monitorada e sistemática, visando a atender projetos sociais, culturais, ambientais e de outras naturezas (GIFE, 2017). A depender do aparato normativo do país, tais investimentos podem ser alavancados por meio de incentivos fiscais. A literatura relaciona a expansão do ISP "[...] à relativa incapacidade do Estado de atender a todas as demandas sociais e à necessidade de fortalecimento da sociedade civil” (GIFE, 2014, p. 2).

Sobre a operacionalização do ISP, primeiramente, tais investimentos se diferenciam de ações assistencialistas ou filantrópicas - na acepção original do termo -, como doações eventuais, pois imprimem preocupações com continuidade, planejamento e estratégias atreladas a resultados. Inclusive, o conceito foi criado na década de 1990 "[...] para designar uma forma de atuação social do setor privado, principalmente empresarial, que buscava se diferenciar de formas mais tradicionais de filantropia” (NOGUEIRA, 2009, p. 1). ). De forma simplificada, a atuação das organizações subdivide-se em três modelos: predominantemente doadoras para outras organizações, predominantemente executoras dos próprios programas e

3 A Transparência Internacional (TI), fundada em 1993, é um movimento global destinado ao combate à corrupção. Com atuação em mais de 100 países, a organização atua em parceria com governos, empresas e sociedade civil.

4 Segundo o plano de trabalho definido no acordo, a Transparência Internacional ficou responsável por desenvolver um relatório que trate: (i) das proposições gerais sobre o sistema de governança, (ii) do plano estratégico para a área temática da prevenção à corrupção e; (iii) dos calendários de desembolso e de encontros de acompanhamento do desenho institucional entre TI, MPF e J\&F. Dentre os temas a serem abordados estão: modelo de governança, arquitetura institucional, acessibilidade dos recursos e abrangência temática, investimentos e comunicação. O plano de trabalho completo está disponível em: <http://www.mpf.mp.br/df/sala-de-imprensa/docs/Plano\%20de\%20Trabalho\%20-\%20MdE\%20assinado\%20-\%20para\%20publicacao.pdf>. 
instituições híbridas. Aliás, sobre tais perfis de atuação, a principal pesquisa sobre investimento social privado no Brasil, o Censo GIFE (2017), apontou que apenas 16\% das organizações são predominantemente doadoras para outras organizações e seus programas. A maior parte, $43 \%$, é predominantemente executora de seus programas:

\section{Gráfico 1: Apoio a organizações da sociedade}

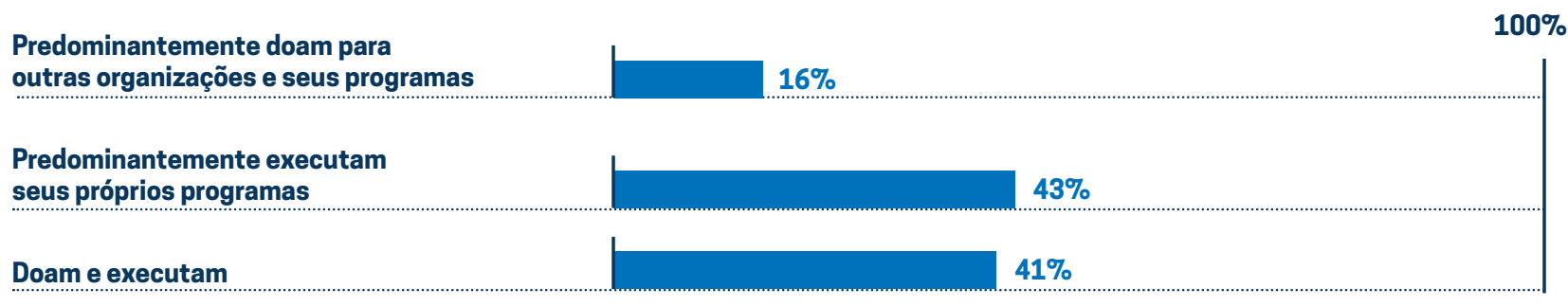

FONTE: GIFE, 2017

De qualquer modo, no cenário atual, as associações e fundações filantrópicas privadas são algumas das principais fontes de apoio para o desenvolvimento de Organizações da Sociedade Civil (OSCs), movimentos sociais, coalizões de defesa de direitos e fóruns sociais (ANHEIER; DALY, 2004). Nesse sentido, o ISP pode ser considerado uma força de transformação social, capaz de mover agendas relevantes e atender às necessidades não satisfeitas pela atuação estatal (Ibidem, p. 158-159).

De acordo com o Censo GIFE (GIFE, 2017), as 116 organizações respondentes contabilizaram um total de R 2,9 bilhões em investimentos naquele ano. A título comparativo, as fundações americanas investiram R\$ 219 bilhões em 2014 (GIFE; FOUNDATION CENTER, 2017). No Brasil, dentre as organizações respondentes do Censo GIFE, $14 \%$ são institutos e fundações ${ }^{5}$ independentes e comunitárias, $15 \%$ são empresas, $19 \%$ são institutos e fundações familiares e $53 \%$ são institutos e fundações empresariais (GIFE, 2017). Ademais, os dados demonstram que as principais áreas de atuação das instituições que responderam ao Censo são: educação (84\%), seguida por formação dos jovens para o trabalho e/ou cidadania (60\%) e cultura e arte (51\%). As áreas com menor porcentagem de atuação são saúde (37\%) e comunicação (27\%) (GIFE, 2017).

5 Institutos e fundações serão utilizados neste artigo quando abordados enquanto tipos de organizações do ISP, considerando os termos utilizados para expressar os nomes fantasia das organizações e não suas personalidades jurídicas. Mas, ao longo do texto, os termos associações e fundações serão usados de modo geral para remeter às personalidades jurídicas dos institutos e fundações. 
Gráfico 2: Prioridades estratégicas de atuação

\begin{tabular}{l} 
Educação \\
Formação de jovens para o trabalho e/ou para a cidadania \\
Cultura e Artes \\
Apoio à gestão de organizações da sociedade civil (OSCs) \\
\hline Desenvolvimento local/ comunitário/ de base \\
Meio ambiente \\
\hline Geração de trabalho e renda \\
\hline Esporte e Recreação \\
\hline Defesa de direitos
\end{tabular}

Em comparação, entre as fundações americanas...

\begin{tabular}{|c|c|c|c|}
\hline $\begin{array}{c}\mathbf{8 0 \%} \\
\text { educação }\end{array}$ & $\begin{array}{c}65 \% \\
\text { assistência } \\
\text { social }\end{array}$ & $\begin{array}{l}61 \% \\
\text { saúde }\end{array}$ & $\begin{array}{c}\mathbf{5 1 \%} \\
\text { cultura } \\
\text { e artes }\end{array}$ \\
\hline
\end{tabular}

FONTE: GIFE, 2017

Nesse contexto, cabe destacar a pesquisa publicada pelo Instituto de Pesquisa Econômica Aplicada (Ipea) em 2018. O estudo identifica a existência de 820 mil organizações da sociedade civil no país, das quais 709 mil (86\%) são associações privadas, 99 mil (12\%) são organizações religiosas e 12 mil (2\%) são fundações (IPEA, 2018).

Ainda nessa seara, quanto às perspectivas de expansão, segundo o Benchmarking do Investimento Social Corporativo (BISC) (COMUNITAS, 2017) ${ }^{6}$, a tendência dos investimentos sociais privados, apesar das recentes oscilações, é de crescimento no Brasil. A média anual dos valores investidos pelo grupo de empresas avaliadas pelo BISC no período de 2007 a 2011 foi de R\$ 2,3 bilhões. Nos últimos cinco anos, essa média subiu para R\$ 2,8 bilhões ao ano.

6 A pesquisa abrange 268 empresas e 18 institutos e fundações empresariais. 
Gráfico 3: Volume de investimentos sociais das empresas avaliadas pelo BISC

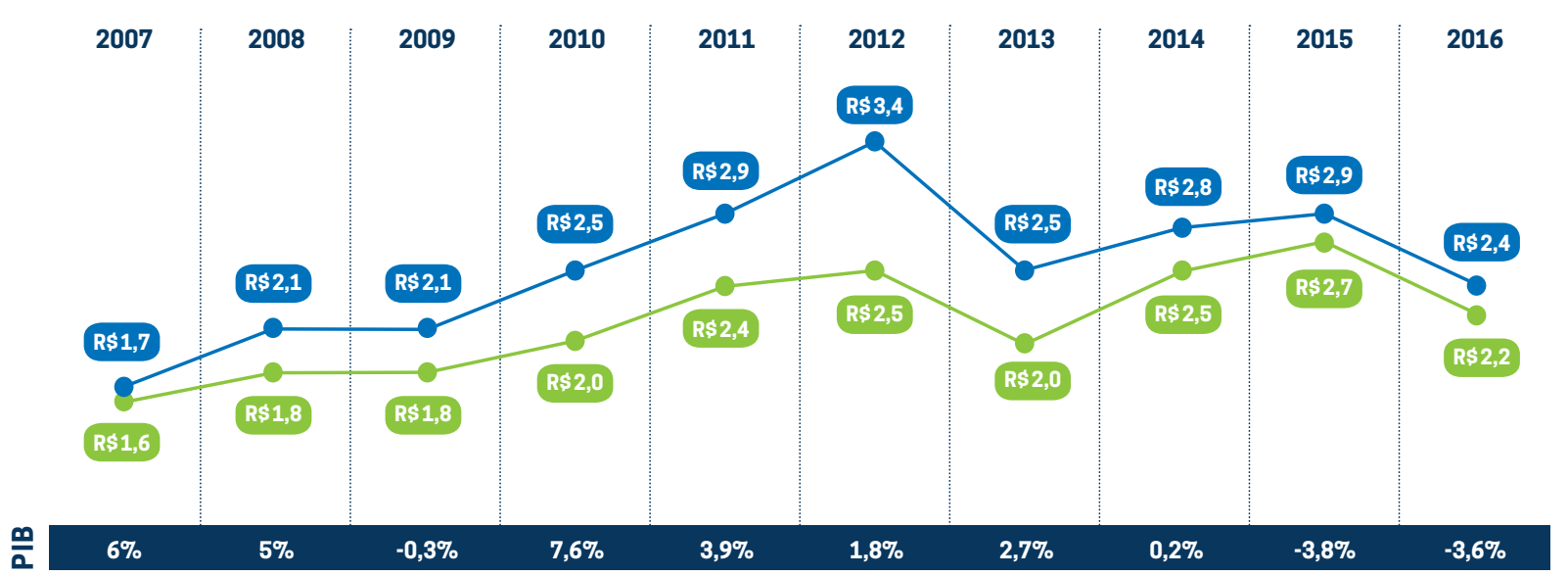

Evolução dos investimentos: todas as empresas

Evolução dos investimentos das empresas que responderam todos os anos

FONTE: COMUNITAS, 2017

Nota: valores em bilhões de reais (ajustados pela inflação).

Ademais, o gráfico evidencia que houve um período de investimentos crescentes - quase linear - entre 2007 e 2012, uma ruptura e em seguida a retomada/estabilização entre 2013 e 2016. Nos períodos analisados, os anos mais destoantes quanto à evolução dos investimentos de todas as empresas respondentes da pesquisa BISC 2017 foram 2012 e 2016 (COMUNITAS, 2017). O primeiro pelo maior volume de investimento e o segundo pela queda na tendência de retomada. Em especial, é necessário chamar atenção para a queda no volume de investimentos sociais das empresas avaliadas pelo BISC em 2016. Isso porque esse foi justamente o ano em que o Brasil registrou uma das mais severas recessões de sua história, devido ao encolhimento de 3,8\% do PIB em 2015, seguido por outra queda de 3,6\% em 2016 (retração de 7,2\% no biênio), segundo dados do IBGE (CURY; SILVEIRA, 2017). É possível que haja uma correlação entre o momento econômico do país e a diminuição dos investimentos.

A esse respeito, o Fundo J\&F, que destinará R\$ 2,3 bilhões a projetos sociais ao longo de 25 anos, representará mais uma fonte de recursos para o ISP no Brasil. Ainda há muita incerteza sobre como serão distribuídos os recursos, se serão exauridos no tempo mínimo estabelecido, se haverá áreas e temas priorizados ou mesmo se haverá reserva anual de uma parcela dos valores para a construção de um endowment (fundo patrimonial). Porém, mesmo que se projete a existência do fundo apenas durante o tempo legalmente estabelecido de 25 anos e isso represente um aporte médio de pouco mais de 90 milhões por ano, será difícil imaginar um impacto transformador em termos de volume de recursos para ISP, afinal, é um setor que movimenta valores anuais na casa de R\$ 2,4 bilhões (em 2016) (COMUNITAS, 2017).

Ainda que seja pouco representativo quando dimensionado em conjunto com os investimentos sociais de todas as empresas avaliadas pelo BISC, o caso do Fundo J\&F pode ser paradigmático. Os inúmeros processos de corrupção já conhecidos no Brasil - além daqueles a ser futuramente revelados -, que geram acordos de leniência volumosos, podem, a partir do caso envolvendo a JBS, receber soluções semelhantes, de modo que, além das reparações específicas aos entes públicos lesados, os investimentos sociais sejam sempre destino de parcela desses recursos. Esse pode se tornar um novo padrão de acordos de leniência nesse campo que dá apenas seus primeiros passos no país.

Cabe, ainda, reforçar uma aproximação conceitual importante em relação ao investimento não voluntário - caso do Fundo J\&F, resultado de uma decisão judicial - versus o investimento voluntário - como é o caso do investimento social privado. Ainda que se diferenciem quanto à motivação da destinação dos recursos, 
ambos podem se destinar a projetos e finalidades semelhantes e, portanto, se complementam em um mesmo movimento de produção de bens públicos, fortalecimento da sociedade civil ou mesmo de busca direta por transformações sociais. Dito isso, alavancar o volume de investimentos oriundos desses dois modelos requer diferentes ações do poder público, tais como a ampliação dos incentivos fiscais - para incentivar o ISP - e o aprimoramento e maior recorrência da utilização dos fundos reparatórios.

$\mathrm{O}$ primeiro bloco deste artigo buscou apresentar brevemente as origens do fundo compensatório J\&F e, em seguida, contextualizá-lo em um cenário mais amplo de fortalecimento da sociedade civil. Em caráter comparativo, buscou-se evidenciar o potencial de impacto que o Fundo J\&F e outros fundos compensatórios podem ter no fortalecimento de projetos voltados a atender as demandas sociais como via alternativa à atuação do Estado.

Tendo em vista o ineditismo e o potencial de impacto do Fundo J\&F, a segunda parte deste artigo apresenta um conjunto de medidas para a sua instauração. As ideias partem de duas fontes: a doutrinária (teórica) e a prática, materializada por entrevistas que mostram a visão de gestores de fundos - muitos deles viabilizados pelo ISP -, que apresentam alguns desafios e os melhores caminhos para construir e consolidar um fundo destinado ao fortalecimento da sociedade civil no Brasil.

\section{A CONSTRUÇÃO DE UM FUNDO REPARATÓRIO}

\subsection{AS BOAS PRÁTICAS DE GOVERNANÇA DE FUNDOS PRIVADOS}

O GIFE (2014) desenvolveu o Guia das Melhores Práticas de Governança para Fundações e Institutos Empresariais, que se transformou em uma importante ferramenta para orientar as organizações da sociedade civil. A organização chama atenção para o fato de que, com o crescimento do número de fundações e associações privadas que realizam investimentos sociais, cresceram as preocupações quanto ao controle, transparência, gestão e prestação de contas das organizações. No mencionado relatório, o GIFE (2014) foca um desafio que se traduz na seguinte questão: como conciliar os princípios de governança com as práticas existentes nas organizações?

No caso específico do Fundo J\&F, esse desafio se mostra como uma oportunidade, pois não se trata de adaptar as práticas, mas sim de construir, desde o início, um fundo pautado no que chamamos de boas práticas de governança. Em vista do quanto exposto, escolhemos algumas temáticas intrinsecamente relacionadas a governança para explorar, à luz da doutrina e das lições trazidas pelos gestores entrevistados. São elas: (i) políticas de conflito de interesses; (ii) due diligence; (iii) código de ética e conformidade legal e; (iv) composição do conselho. Por fim, para explorar a questão da sustentabilidade financeira, o artigo perpassa o tema da formação de um endowment.

Do ponto de vista formal, a gestão do Fundo J\&F poderá ser feita por uma associação, mas entende-se que uma fundação ofereceria garantias jurídicas mais adequadas para a distribuição dos recursos do fundo por 25 anos - ou, de forma perene, além do prazo mínimo estabelecido no acordo de leniência, se assim for decidido. Por se tratar de gestão privada de recursos com forte interesse público, o acompanhamento permanente das fundações pelo departamento especializado do Ministério Público dos estados pode significar garantia de preservação do interesse da coletividade.

Seja qual for o desenho jurídico escolhido - fundação ou associação - o desafio das más práticas para favorecimento de gestores ou terceiros é enorme. As fundações ou associações são vulneráveis, em tese, como qualquer outra empresa ou instituição com finalidade exclusivamente privada, passivas de infringirem a lei por seus funcionários cometerem suborno, peculato ou outras práticas ilegais. A administração de grandes quantias de doações em instituições nas quais as estruturas de governança não são suficientemente transparentes cria um ambiente no qual a corrupção pode se infiltrar. Organizações devem ter uma forte política anticorrupção e um código de ética para manter a instituição transparente e accountable (RAHMAN, 2018). 
Dessa forma, considerando os desafios que as fundações podem encontrar, serão aqui analisadas algumas das boas práticas de governança capazes de contribuir com um ambiente controlado e íntegro.

\subsubsection{POLITICAS DE CONFLITO DE INTERESSES}

Sem a intenção de exaurir o debate, o primeiro tópico a ser abordado é o conflito de interesses. Tal ato ocorre quando um indivíduo - membro do conselho, diretor ou membro da equipe - percebe que sua obrigação de promover os objetivos da organização está em desacordo com os seus interesses financeiros ou pessoais (PATHWAY, 2017).

Algumas fundações contam com a política de disclosure, a qual exige que membros da equipe, da diretoria, do comitê ou até voluntários apresentem ao diretor executivo uma lista com seus principais negócios e atividades, indicando seu envolvimento com outras organizações, fornecedores ou quaisquer outras associações que possam produzir um conflito de interesses, antes mesmo que iniciem suas atividades (COUNCIL ON FOUNDATIONS, 2018).

Outra política capaz de atenuar os riscos do conflito de interesses é a chamada recusal. A medida se dá quando o conselho curador decide que um de seus membros tem um inevitável conflito de interesses, que o levará a ausentar-se formal e fisicamente no momento da deliberação em questão. O membro deve oferecer informações e responder a perguntas do presidente do conselho para que se tome a melhor decisão sobre sua continuidade no projeto em específico ou como membro da fundação (Ibidem, p. 2).

\subsubsection{DUE DILIGENCE}

Um segundo ponto a ser considerado diz respeito à due diligence, ou seja, o procedimento por meio do qual o doador verifica se a instituição pode ser considerada elegível para os subsídios oferecidos. No contexto brasileiro, a filantropia é bastante executora e, por isso, um conceito de due diligence baseado apenas em grantmaking ${ }^{7}$ não atende completamente ao campo do ISP no Brasil. No caso em questão, todavia, a due diligence é crucial, pois o Fundo J\&F será unicamente doador.

É de se observar, ainda, que due diligence não diz respeito apenas à conformidade financeira da instituição em análise; é sobre ajudar o doador (grantmaker) a verificar se a sua missão e a missão da instituição que pretende receber os recursos (grantseeker) estão em sintonia (GUIDESTAR, 2017).

A GuideStar, uma organização sem fins lucrativos que estimula as OSCs, oferece alguns princípios sobre como uma fundação pode construir seu processo de due diligence: manter a simplicidade, evitar abordagem única (é necessário ajustar a sua abordagem com base na organização), não prejudicialidade (preencher e cumprir os requisitos de due diligence pode ser caro e difícil para certas organizações) e feedback do beneficiado.

\footnotetext{
$7 \mathrm{O}$ termo grantmaking consiste na prática de apoio financeiro dirigido às atividades de organizações da sociedade civil, grupos e movimentos, enquanto o grantmaker ou doador pode ser pessoa física ou jurídica de direito privado, ou ainda fundos de pessoa jurídica de direito público.
} 


\subsubsection{CÓDIGO DE ÉTICA E CONFORMIDADE LEGAL}

Tratando de aspectos mais estruturais, e não menos importantes, este e o tópico seguinte abordam os códigos de conduta e códigos de ética e, em seguida, a composição dos conselhos. Os códigos de ética e conformidade legal são os tipos mais comuns de iniciativa auto-reguladora, tanto de empresas privadas quanto de instituições filantrópicas. Esses códigos normalmente apresentam um conjunto de padrões definidos como um guia de comportamentos e práticas, que podem ser regras gerais ou até regulamentos mais detalhados para aspectos específicos das fundações (HARTAY; ROSENZWEIGOVÁ, 2017).

Para uma governança eficaz, as organizações devem dar atenção especial às políticas internas e às questões éticas, incluindo problemas como o conflito de interesses. A reputação é o ativo mais valioso para qualquer instituição e depende de uma cultura que valorize altos padrões éticos. Segundo Griswold e Jarvis (2015), a melhor supervisão vem da própria associação ou fundação e não de órgãos reguladores.

A literatura identifica quatro principais interessados na conformidade legal: (i) interessados internos (equipe, diretoria, apoiadores, subsidiárias, parceiros locais), (ii) doadores, (iii) beneficiários (receptores do investimento social) e (iv) aqueles afetados pelas atividades (setor privado, governo, organizações internacionais, etc.) ou sociedade civil em geral (IBGC, 2015, p. 24).

Códigos voluntários de conduta contribuem para a definição de visão, valores e princípios orientadores, estabelecendo uma estrutura de prestação de contas que esclarece os papéis, responsabilidades e processos decisórios, além de definir comportamentos profissionais aceitáveis. O estabelecimento e adesão a um código de conduta envia sinais de credibilidade, confiabilidade e profissionalismo, tanto para uma audiência externa quanto para os funcionários (CHENE, 2013, p. 3-4).

O código também deve prever o estabelecimento de procedimentos de reclamações para o público externo e interno, a fim de facilitar a comunicação de irregularidades ou ações consideradas como contrárias aos padrões do código. Em alguns casos, a organização pode designar um ombudsman que possa responder às preocupações das partes interessadas e manter as operações da organização concentradas em seu mandato, missão, valores e princípios (Ibidem, p. 6).

A implementação efetiva do código na prática também depende dos mecanismos de supervisão para monitorar a conformidade e detectar e investigar suas violações. O processo de tomada de decisão para decidir se um funcionário violou o código deve ser aberto, justo e transparente. A avaliação regular do impacto é um elemento crucial do regime de execução, com mecanismos regulares de apresentação de relatórios, análise de reclamações feitas, revisões, etc. (Ibidem).

Os códigos de conduta podem ser estruturados da seguinte forma: (i) missão e visão da organização, incluindo os objetivos estratégicos; (ii) valores essenciais, incluindo uma declaração geral dos motivos e cultura interna; (iii) responsabilidades de práticas, incluindo as responsabilidades da organização em relação às partes interessadas; (iv) padrões e regras para gerentes e funcionários, indicando o que é considerado comportamento aceitável, incluindo regras sobre presentes, uso de ativos da empresa, confidencialidade, entre outros elementos que influenciam a conduta de funcionários (MARTINI, 2014, p. 2-3).

Assim, os códigos devem ser a versão redigida e documentada da própria política da organização, sendo enviados e atualizados por comunicação regular e apresentados nos treinamentos, a fim de estabelecer meio de monitoramento que busque detectar violações (MOREIRA, 2018). Para Selma Moreira (2018), 
do Fundo Baobá ${ }^{8}$, os códigos de conduta podem se dirigir também aos doadores do fundo, como vem sendo praticado na organização em que atua, de forma a garantir homogeneidade na conduta em todas as esferas.

\subsubsection{COMPOSIÇÃO DO CONSELHO}

Selecionar membros qualificados para compor o conselho da fundação ou associação é fundamental para a governança da instituição. Uma cultura de liderança engajada inclui ter pessoas que saibam claramente quais são seus papéis e sejam responsáveis (GRISWOLD; JARVIS, 2015). Dessa forma, em primeiro lugar, a fundação ou associação deve alinhar a cultura que procura criar com seu ponto de vista ético. Em segundo, deve escolher pessoas que sejam alinhadas às características que a entidade gostaria de incorporar (HAWTHORNE, 2015).

Especialistas em governança concordam que a diversidade entre os membros do conselho é importante (etnia, gênero, formação, experiência profissional, religião, etc.). Nesse sentido, um dado alarmante do GIFE (2017) mostrou que, no Brasil, apenas 24\% dos conselheiros são mulheres. Quanto aos aspectos raciais, $71 \%$ dos institutos e fundações que participaram do Censo GIFE afirmaram possuir unicamente conselheiros brancos. Em algumas posições específicas, como, por exemplo, nas funções de fiscalização ou de investimento, os membros devem ter conhecimento especializado, mas, de forma geral, para se montar um conselho respeitado e eficaz, é importante que ele seja formado por membros de diversas origens, experiências, gênero e pontos de vista (GRISWOLD; JARVIS, 2015).

Nesse sentido, Andre Degenszajn $(2018)^{9}$ entende que "com muita frequência esses conselhos não funcionam se são muito grandes ou representam diversas instituições com diferentes interesses. O ideal é que esse conselho seja funcional, capaz de tomar decisão e, para isso, não pode ter 30 membros; o guia do GIFE fala em 11 como um bom número [...]. Tem que ter pessoas livres de conflitos de interesse, pessoas legitimadas, que possam orientar e agregar em termos programáticos e políticos. Não precisa ser um conselho de operadores de fundação, mas tem que ter gente que entenda disso, com características múltiplas" (DEGENSZAJN, 2018).

O entrevistado acrescentou também que "[...] em um conselho de administração, é fundamental criar uma regra de alternância. Um fundo como esse não pode ter pessoas que se cristalizam no conselho. $\mathrm{O}$ conselho deve ter uma perspectiva de oxigenação. Outra regra [...] perigosa é do tipo 'tem que ter um conselheiro representante de $\mathrm{X}$, outro de $\mathrm{Y}^{\prime}$, mas acho que engessar demais a estrutura pode engessar o conselho" (DEGENSZAJN, 2018).

8 O Fundo Baobá dedica-se a mobilizar pessoas e recursos, no Brasil e no exterior, para apoiar projetos pró-equidade racial de organizações da sociedade civil afro-brasileiras.

9 Andre Degenszajn é bacharel e mestre em Relações Internacionais. Foi secretário-geral do Grupo de Institutos Fundações e Empresas (GIFE) entre 2013 e 2017. Foi fundador e atualmente integra o Conselho Diretor da Conectas Direitos Humanos. É membro do Conselho Diretor da WINGS - Worldwide Initiatives for Grantmaker Support e da Oxfam Brasil. É diretor-presidente do Instituto Ibirapitanga. 
Ana Toni $(2018)^{\mathbf{1 0}}$ sugere, como modelo de governança, um conselho que tenha "suas regras, manuais, um sistema de transparência, seja levado a sério, tenha entre sete e nove pessoas boas e dedicadas. Não é preciso um conselho consultivo. Conselho tem que tomar decisão. Criar mais uma instância só para trazer grandes nomes não é necessário". Na visão de Pedro Abramovay $(2018)^{\mathbf{1 1}}$, por sua vez, "o mais importante é pensar quais funções de governança devem estar na mão do conselho e separar a gestão em si dessas funções. Se estiver tudo na mão do conselho, deve ser um conselho maior, de dez a doze pessoas. Se for um menor, é melhor dividir as funções" (ABRAMOVAY, 2018).

\subsubsection{ENDOWMENT}

As associações ou fundações que realizam investimentos sociais por meio de recursos próprios ou mesmo captados para o fim de redistribuição devem desenvolver ações e políticas que garantam a sua sustentabilidade financeira. Nesta seção serão discutidos o controle de qualidade e as possibilidades do uso do endowment (fundo patrimonial) como instrumento de transformação social.

Quando tratamos de organizações com recursos em volume suficiente para garantir estabilidade financeira para operações de longo prazo - geralmente fundações -, abre-se a discussão sobre como preservar o endowment e como aumentar o impacto por meio de sua gestão. Em geral, os recursos de uma fundação ou organização são investidos para maximizar os retornos financeiros e, assim, sustentar a existência da fundação em perpetuidade ou, ao menos, para ampliar o tempo de atuação (BUCHANAN, 2016).

As instituições que se valem de seu endowment como instrumento de ação "costumam ter critérios de não investimento, por exemplo, em empresas de armas, tabaco e álcool". Além do veto a certos setores, é possível "[...] fazer uma gestão na qual o patrimônio da instituição trabalha conforme a sua missão, ou seja, além de não financiar certos setores contraditórios à missão, todo ativo trabalha para a missão, sendo investido em empresas com missão compatível à sua" (DEGENSZAJN, 2018). A preocupação, nesses casos, passa a ser tentar usar parte do endowment como alavanca do objetivo da fundação (TONI, 2018).

Amalia Fischer explica que a destinação dos recursos de grantmaking, por vezes, recebe direcionamento de "doadores que exigem que o recurso seja aplicado em projetos e de outros que dão uma maior liberdade", mas, entende que uma boa destinação seria partilhar o recurso entre "fortalecimento institucional, execução de programas e endowment” (PFAEFFLE, 2018).

10 Ana Toni é graduada em Economia e Estudos Sociais pela Universidade de Swansea, mestre em Políticas da Economia Mundial pela London School of Economics and Political Science (LSE) e doutora em Ciência Política pela UERJ. Foi diretora da Fundação Ford no Brasil por quase dez anos, gerenciando as áreas de direitos humanos, desenvolvimento sustentável, democratização midiática e discriminação racial e ética. No Greenpeace, trabalhou inicialmente como diretora da unidade de políticas do Greenpeace Internacional e, posteriormente, como assessora sênior do Greenpeace Alemanha. É diretora executiva do Instituto Clima e Sociedade (iCS) e sócia-fundadora da Gestão de Interesse Público (GIP). Atualmente, integra a Rede de Mulheres Brasileiras Líderes pela Sustentabilidade e é membro dos conselhos da Agência Pública, da WINGS, da Gold Standard Foundation, do ITS, do Fundo Baobá por Igualdade Racial e da Wikimedia Foundation.

11 Pedro Abramovay é advogado, formado em direito pela USP e mestre em direito pela UNB. Foi assessor jurídico da liderança do governo no Senado Federal, assessor especial do Ministro da Justiça, secretário de assuntos legislativos, secretário nacional de justiça (2010), professor da FGV Direito RJ e diretor de campanhas da Avaaz. Atualmente é diretor para a América Latina da Open Society Foundations. 


\section{CONCLUSÃO}

Este artigo destacou experiências práticas e teóricas sobre a organização de fundos voltados para a sociedade civil, tendo como principal finalidade fazer inferências sobre qual seria o melhor modelo para o Fundo J\&F, porém, sem a pretensão de debater minuciosamente todos os aspectos de sua estrutura. As principais preocupações que guiaram esta pesquisa foram o desenvolvimento de um sistema de governança, a criação de um cenário propício para a segurança jurídica e a construção da legitimidade social. Seria, portanto, recomendável a criação de uma institucionalidade para gerir os recursos e comandar a execução dos projetos sociais.

A pesquisa partiu do diagnóstico decorrente de estudos sobre o campo de investimento social privado e filantropia no Brasil e no mundo para avaliar o impacto e inserção temática do novo fundo. Tudo indica que um novo fundo, com o porte do que se pretende criar com recursos oriundos do acordo de leniência da J\&F, poderá trazer maior vitalidade para as OSCs no Brasil, somando-se a outras formas de financiamento, como o ISP. Na hipótese de que o fundo se constitua com uma perspectiva de perenidade, trará também estabilidade para um setor que sofre recentes oscilações no volume de investimentos. Ademais, a avaliação das áreas temáticas servirá como importante guia para a ampliação e fortalecimento de setores que demandam maior investimento, como o da anticorrupção, por exemplo.

Do exposto, a conclusão a que se chega é a de que o Fundo J\&F deve ser pautado na adoção de boas práticas de governança desde sua concepção, criando uma estrutura que não abra margem a atos de corrupção. Para tal, deve-se moldar uma política de governança que evite conflitos de interesse e que incentive uma composição plural dos membros e conselheiros/as. Em acréscimo, a busca pela perenidade do fundo deve ser um ponto prioritário, mantendo, ainda, a transparência e a clareza quanto aos recursos investidos e seus destinatários. O Fundo J\&F se apresenta como uma via muito promissora para o fortalecimento da sociedade civil e, principalmente, representa uma grande oportunidade de construção de um modelo de devolução para a sociedade dos recursos desviados em casos de corrupção. 


\section{REFERÊNCIAS BIBLIOGRÁFICAS}

ABRAMOVAY, Pedro. Entrevista. Entrevistador: Michael Freitas Mohallem. Rio de Janeiro: Open Society, ago. 2018.

ABANHEIER, Helmut K.; DALY, Siobhan. Philanthropic Foundations: A New Global Force? Londres: London School of Economics and Political Science, 2004. Disponível em: $\lfloor$ http://www.lse.ac.uk/internationalDevelopment/research/CSHS/civilSociety/yearBook/chapterPdfs/2004-05/Chapter7.pdf>.

BUCHANAN, P. Opinion: 5 Issues Foundations Must Confront to Stay Relevant. The Chronicle of Philanthropy, 2016. Disponível em: 〈https://www.philanthropy.com/article/Opinion-5-Issues-Foundations/236339>.

CHENE, Marie. Key features of NGO accountability systems. n. 358. Transparency International, 30 jan. 2013.

COMUNITAS. Relatório BISC 2017. Disponível em: 〈http://www.comunitas.org/portal/bisc-publicacoes/〉.

COUNCIL ON FOUNDATIONS. Sample Conflict of Interest Policies from the Council. 2010. Disponível em: <http://www. cof.org/sites/default/files/documents/files/Sample-Conflict-of-Interest-Policies-From-the-Council.pdf>.

CURY, Anay; SILVEIRA, Daniel. PIB recua 3,6\% em 2016, e Brasil tem pior recessão da história. Portal G1, Economia, 07 mar. 2017. Disponível em: <https://g1.globo.com/economia/noticia/pib-brasileiro-recua-36-em-2016-e-tem-pior-recessao-da-historia.ghtml $>$. Acesso em: 14 jan. 2019.

DEGENSZAJN, André. Entrevista. Entrevistadores: Michael Freitas Mohallem e Gabriela Gattulli. Rio de Janeiro: Instituto Ibirapitanga, jun. 2018.

GRISWOLD, John S.; JARVIS, William F. Governance and Compliance Issues for Foundation Financial Management. Commonfund Institute, Council of Foundations, 2015. Disponível em: <https://www.cof.org/sites/default/files/documents/files/ COF_WP_GOV.pdf>.

GRUPO DE INSTITUTOS, FUNDAÇÕES E EMPRESAS (GIFE). Guia das melhores práticas de governança para fundações e institutos empresariais. 2. ed. São Paulo: IBGC e GIFE, 2014.

Censo GIFE 2016. 1. ed. São Paulo: GIFE, 2017, 256 p.

GRUPO DE INSTITUTOS, FUNDAÇÕES E EMPRESAS (GIFE); FOUNDATION CENTER. Key Facts sobre o Investimento Social Privado. São Paulo: GIFE; Foudation Center, 2017. Disponível em: 〈https://gife.org.br/censo-gife/〉.

GUIDESTAR. A Guide to Good Practices in Foundation Operations. 2017. Disponível em: 〈https://learn.guidestar.org/hubfs/ Docs/foundation-good-practices.pdff>.

HARTAY, Eszter.; ROSENZWEIGOVÁ, Ivana. The Regulatory Framework for Fundraising in Europe. European Centre for Not-for-profit Law (ECNL), 2017. Disponível em: <http://ecnl.org/wp-content/uploads/2017/11/The-Regulatory-Framework-for-Fundraising-in-Europe ECNL-research.pdf>.

HAWTHORNE, R. The First Steps to Building a Foundation of Nonprofit Culture. Bloomerang, 2015. Disponível em: <https:// bloomerang.co/blog/the-first-steps-to-building-a-foundation-of-nonprofit-culture/> Acesso em: 18 ago. 2018.

INSTITUTO BRASILEIRO DE GOVERNANÇA CORPORATIVA (IBGC). Código das melhores práticas de governança corporativa. 5. ed. São Paulo: IBGC, 2015, 24 p. Disponível em: <http://www.ibgc.org.br/userfiles/files/Publicacoes/Publicacao-IBGCCodigo-CodigodasMelhoresPraticasdeGC-5aEdicao.pdf>.

INSTITUTO DE PESQUISA ECONÔMICA APLICADA (IPEA). Perfil das organizações da sociedade civil no Brasil. Organizador: Felix Garcia Lopez. Brasília: Ipea, 2018. 176 p. 
MARTINI, Maíra. Best Practices and Challenges for Whistleblowing Systems in Multinational Companies. Transparency International, 2014. Disponível em: <https://www.transparency.org/whatwedo/answer/best practice and challenges for whistleblowing systems in multinational co>.

MINISTÉRIO PÚBLICO FEDERAL (MPF). Termo aditivo ao termo de ajustamento preliminar (TAP) firmado entre o MPF, a Samarco Mineração S/A, a VALE S/A e a BHP Billiton Brasil Ltda. 2017a. Disponível em: <http://www.mpf.mp.br/mg/ sala-de-imprensa/docs/aditivoTAP.pdf>.

Memorando de entendimento. MPF, J\&F Investimentos e Transparency International, 2017b. Disponível em: <http:// www.mpf.mp.br/df/sala-de-imprensa/docs/Memo\%20entendimentos\%20J-F.pdf>. Acesso em: 23 ago. 2018.

MOREIRA, Selma. Entrevista. Entrevistadores: Marcus Repa e Michael Freitas Mohallem. MPF, jul. 2018. Acordo de Leniência. Disponível em: 〈http://www.mpf.mp.br/df/sala-de-imprensa/docs/acordo-leniencia >

NOGUEIRA, Fernando do A.; SHOMMER, Paula Chies. Quinze Anos de Investimento Social Privado no Brasil: Conceito e Práticas em Construção. In: XXXIII ENCONTRO DA ANPAD, 2009, São Paulo.

PFAEFFlE, Amalia F. Entrevista. Entrevistadores: Michael Freitas Mohallem, Denise Dora, Pedro Strozenberg e Fabiano Angélico. Rio de Janeiro: Fundação Getúlio Vargas, jul. 2018.

RAHMAN, Kaunais. Anti-Corruption helpdesk. Good Practices in Governance, transparency and accountability for foundations. Transparency International, 2018.

SIEMENS. Siemens Integrity Initiative Annual Report. 2016. Disponível em: < https://assets.new.siemens.com/siemens/assets/ public.1543064069.4c550d92cc059e9a38a1989cdcf770732f485c59.siemens-integrity-initiative-annual-report-2016.pdf>.

TONI, Ana. Entrevista. Entrevistador: Michael Freitas Mohallem. Rio de Janeiro: Instituto Clima e Sociedade, ago. 2018. 



\section{OS AUTORES}

\section{Michael Freitas Mohallem}

Professor e coordenador do Centro de Justiça e Sociedade (CJUS) da FGV Direito Rio. Doutorando e LL.M em Direito Público e Direitos Humanos pela University College London (UCL), especialista em Ciência Política pela Universidade de Brasília (UnB) e graduado em Direito pela Pontifícia Universidade Católica de São Paulo (PUC-SP). Foi pesquisador visitante no European University Institute (EUI), professor visitante no Minerva Center for Human Rights da Hebrew University of Jerusalem e pesquisador do projeto Oxford Reports on International Law in Domestic Courts. Atuou como diretor da organização Avaaz no Brasil.

\section{Isabel Cristina Veloso de Oliveira}

Pesquisadora do Centro de Justiça e Sociedade (CJUS) da FGV Direito Rio, onde atua na área de governança, políticas públicas e legislação de enfrentamento da corrupção. Bacharel em Relações Internacionais (UFF), especialista em Administração Pública (UFF), mestre em Ciência Política (IESP-UERJ) e doutora em Ciência Política pelo Instituto de Estudos Sociais e Políticos da Universidade do Estado do Rio de Janeiro (IESP/UERJ). 
Supervisão: José Marcelo Zacchi e Erika Sanchez Saez

Coordenação: Graziela Santiago

Suporte: Carolina Magosso

Comitê de seleção: Ana Lúcia D'Império Lima,

Aron Belinky, Beatriz Azeredo e Paula Galeano

Projeto gráfico e diagramação: Dafne Rozencwaig Souza

Revisão: Amanda Proetti

Impressão: Forma Certa

(c) 2019 GIFE - Grupo de Institutos Fundações e Empresas

DOI: doi.org/10.4322/978-85-88462-37-3-02

\section{(C) $(1) \Theta$}

Este material é disponibilizado sob a licenca Creative Commons Atribuição Não Comercial 4.0 Internacional. http://creativecommons.org/licenses/by-nc/4.0

As opiniões e análises expressas nesta publicação não necessariamente refletem as do GIFE. 